\section{RNA Pol II subunit Rpb7 promotes centromeric transcription and RNAi-directed chromatin silencing}

\author{
Ingela Djupedal, ${ }^{1,4}$ Manuela Portoso, ${ }^{2,4}$ \\ Henrik Spåhr, ${ }^{3}$ Carolina Bonilla, ${ }^{1}$ \\ Claes M. Gustafsson, ${ }^{3}$ Robin C. Allshire, ${ }^{2}$ \\ and Karl Ekwall ${ }^{1,5}$
}

\begin{abstract}
${ }^{1}$ Karolinska Institutet, Department of Biosciences/School of Life Sciences, University College Sodertorn, S-141 89 Huddinge, Sweden; ${ }^{2}$ Wellcome Trust Centre for Cell Biology, Institute of Cell and Molecular Biology, University of Edinburgh, Edinburgh EH9 3JR, United Kingdom; ${ }^{3}$ Karolinska Institutet, Department of Medical Nutrition, Novum, S-141 86 Huddinge, Sweden
\end{abstract}

Fission yeast centromeric repeats are transcribed into small interfering RNA (siRNA) precursors (pre-siRNAs), which are processed by Dicer to direct heterochromatin formation. Recently, Rpb1 and Rpb2 subunits of RNA polymerase II (RNA Pol II) were shown to mediate RNA interference (RNAi)-directed chromatin modification but did not affect pre-siRNA levels. Here we show that another Pol II subunit, Rpb7 has a specific role in presiRNA transcription. We define a centromeric presiRNA promoter from which initiation is exquisitely sensitive to the rpb7-G150D mutation. In contrast to other Pol II subunits, Rpb7 promotes pre-siRNA transcription required for RNAi-directed chromatin silencing.

Supplemental material is available at http://www.genesdev.org.

Received March 18, 2005; revised version accepted August 2, 2005.

In RNA interference (RNAi), Dicer processes doublestranded RNA to produce short small interfering RNAs (siRNAs) that act to silence gene expression post-transcriptionally (Fire et al. 1998; Zamore et al. 2000; Bernstein et al. 2001). RNAi also mediates transcriptional silencing via formation of heterochromatin. Centromeres in many organisms are composed of repetitive DNAs, which act as a substrate for the formation of kinetochores, flanked by domains of centromeric heterochromatin (Cleveland et al. 2003). In fission yeast (Schizosaccharomyces pombe) genes inserted within this heterochromatin are transcriptionally silenced

[Keywords: RNAi; heterochromatin; centromeres; RNA polymerase II; Rpb7]

${ }^{4}$ These authors contributed equally to this work.

${ }^{5}$ Corresponding author.

E-MAIL karl.ekwall@sh.se; FAX 46-8-6084510.

Article and publication are at http://www.genesdev.org/cgi/doi/10.1101/ gad.344205.
(Allshire et al. 1995). Paradoxically, the centromeric repeats themselves are transcribed to form long siRNA precursors (pre-siRNAs), which are required for the RNAi-mediated chromatin modifications resulting in transcriptional silencing (Provost et al. 2002; Volpe et al. 2002). Defective RNAi leads to loss of silencing and defective heterochromatin formation in several organisms (Mochizuki et al. 2002; Pal-Bhadra et al. 2002; Zilberman et al. 2003) and transcripts homologous to centromere repeats have been detected in chicken cells as well as mice (Fukagawa et al. 2004; Kanellopoulou et al. 2005). Interestingly, in plants, specialized RNA polymerase IV (RNA Pol IV) subunits have been implicated in RNAidirected silencing (Herr et al. 2005; Onodera et al. 2005). Animal and fungal genomes lack such Pol IV subunits. Very recently, however, two subunits of RNA pol II (Rpb1 and Rpb2) were shown to have specific roles in chromatin modification and siRNA production, respectively, but did not affect pre-siRNA levels (Kato et al. 2005; Schramke et al. 2005).

Here, we have characterized the temperature sensitive csp3 (centromere: suppressor of position effect) mutant isolated in a screen for trans-acting mutants that are required for centromeric silencing (Ekwall et al. 1999). csp3 is a $G 150 D$ missense mutation in the $r p b 7$ gene, a subunit of Pol II. We show that Rpb7 has a specific defect in centromeric pre-siRNA transcription. We define a centromeric pre-siRNA promoter from which initiation is exquisitely sensitive to rpb7-G150D. Thus, in contrast to the previously characterized silencing defective Pol II subunits, which affect siRNA production and/or downstream events, Rpb7 has a distinct role in generating centromeric pre-siRNAs needed for RNAi-directed chromatin silencing.

\section{Results and Discussion}

The csp3 gene was isolated by complementation of its temperature sensitivity. Complementing plasmids contained the $r p b 7$ gene, and the corresponding open reading frame bears a missense mutation (rpb7-G150D) in csp3 mutant cells. The $r p b 7$ gene was previously reported to encode an essential component of Pol II in S. pombe (Sakurai and Ishihama 1997; Mitsuzawa et al. 2003). The rpb7-G150D mutation lies within an RNA-binding motif (Fig. 1A). To biochemically characterize the $r p b 7$ G150D mutation, we purified Pol II from wild-type and rpb7-G150D cells (Spahr et al. 2003). The subunit composition of wild-type and mutant Pol II was identical, as demonstrated by SDS-PAGE analysis, Coomassie Brilliant Blue staining, and protein identification by mass spectroscopy (Fig. 1B). Western blotting showed that $\mathrm{Rpb} 7$ remained associated with the rpb7-G150D mutant polymerase (Fig. 1C). The phenotype associated with the rpb7-G150D mutation was therefore not due to gross alterations in the Pol II subunit composition. We analyzed mutant Pol II isolated from the rpb7-G150D strain in a reconstituted in vitro system (Spahr et al. 2003). At the permissive temperature $\left(23^{\circ} \mathrm{C}\right)$, basal transcription with mutant Pol II was functional, albeit reduced, as compared with wild type Pol II. At $36^{\circ} \mathrm{C}$, however, the activity of the wild type Pol II was unaffected, whereas the activity of Pol II from the rpb7-G150D strain was almost completely abolished (Fig. 1D). Interestingly, Pol 
A

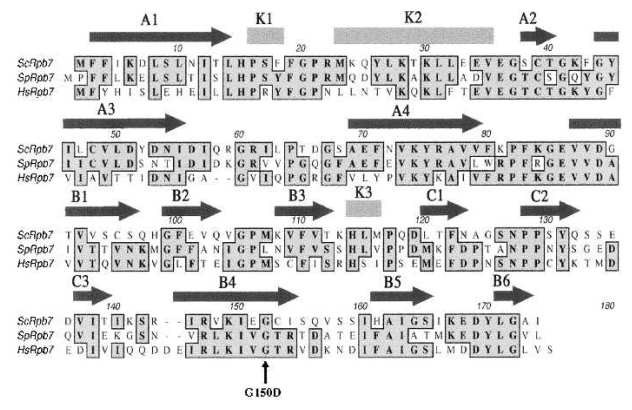

B
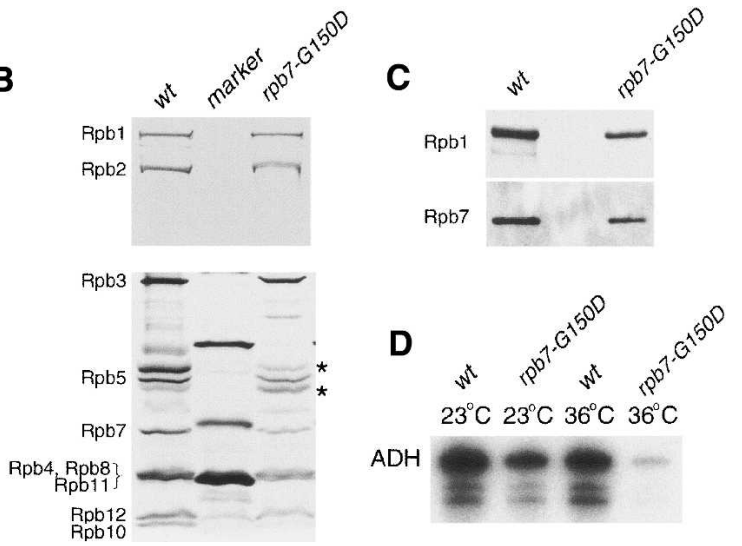

Figure 1. Characterization of the rpb7-G150D mutation. (A) Alignment of the amino acid sequence of Rpb7 from Saccharomyces cerevisiae, S. pombe, and Homo sapiens. The arrows indicate secondary structure motifs discovered in the crystal structure of $\mathrm{Rpb} 7$ from archaebacterium Methanococcus jannaschii (Todone et al. 2001). The $r p b 7-G 150 D$ point mutation substitutes a glycine with an aspartic acid at position 150. (B) Purification of Pol II from wild-type and $r p b 7-G 150 D$ strains. Proteins were separated on a 10\% gel (upper panel) and on a $10 \%-20 \%$ gel (lower panel) and revealed by Coomassie Brilliant Blue staining. Rpb7 (19.1 kDa), Rpb4 (15.3 kDa), and eight other subunits were present in both wild-type and rpb7G150D preparations as confirmed by MALDI-TOF mass fingerprinting of the indicated bands. The asterisks $\left({ }^{\star}\right)$ denote major protein contaminants not related to Pol II. $(C)$ The presence of $\mathrm{Rpb} 7$ in both wild type and $r p b 7-G 150 D$ was confirmed with immunoblotting. (D) Transcription was reconstituted in vitro with a reporter construct containing the $S$. pombe adh $1^{+}$promoter followed by a G-less cassette as previously described (Spahr et al. 2003). Either wild-type Pol II or rpb7-G150D mutant were used at the permissive or restrictive temperature.

II from the rpb7-G150D strain had higher affinity for binding single-stranded RNA (ssRNA) than wild type Pol II at $23^{\circ} \mathrm{C}-25^{\circ} \mathrm{C}$ and $36^{\circ} \mathrm{C}$ (Supplementary Fig. S1). The basic biochemical properties of Pol II, however, seem to be unaffected in $r p b 7-G 150 D$ at $23^{\circ} \mathrm{C}-25^{\circ} \mathrm{C}$.

In order to assay the general effects on transcription of the rpb7-G150D mutation, cDNA expression profiling microarray analyses were performed (Xue et al. 2004). To compare the drastic reduction at the restrictive temperature $\left(36^{\circ} \mathrm{C}\right)$ with $25^{\circ} \mathrm{C}$, the data were normalized using luciferase RNA spiking controls. At $25^{\circ} \mathrm{C}$, only 106 genes were more than twofold down-regulated in $r p b 7$ G150D as compared with wild type, and expression of genes with known functions in centromeric silencing were not significantly altered (Supplementary Table S2). In contrast, only after $1 \mathrm{~h}$ at the growth restrictive temperature $\left(36^{\circ} \mathrm{C}\right)$ a substantial part of the genome $(>1803$ genes) were down-regulated in $r p b 7-G 150 D$ as compared with wild type (Supplementary Fig. S2). Thus, the rpb7-
G150D strain is generally defective for transcription at the restrictive temperature but displays a specific defect in centromeric silencing at $25^{\circ} \mathrm{C}$.

Next, we tested whether rpb7-G150D had any defects in the RNAi pathway that directs heterochromatin formation and transcriptional silencing over the centromeric $d g-d h$ repeats. RT-PCR was used to investigate silencing of a cen1R:ade6 $6^{+}$marker (Fig. 2A). At $25^{\circ} \mathrm{C}$

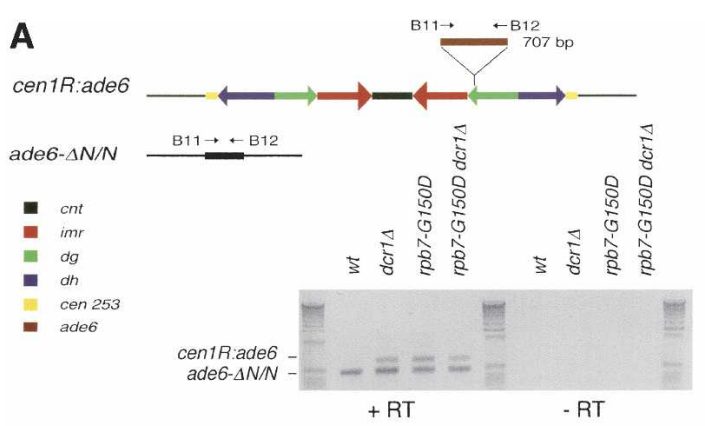

B
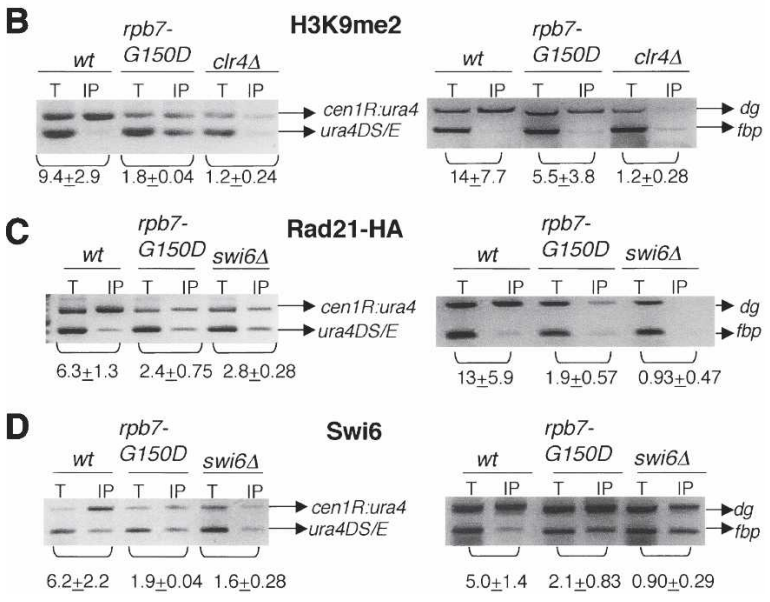

Figure 2. Centromeric heterochromatin defects in rpb7-G150D and $d c r 1 \Delta r p b 7-G 150 D$ double-mutant cells. (A) RT-PCR analysis of centromeric silencing. Schematic representation of the $a d e b^{+}$ marker gene within centromeric $d g-d h$ repeats and the truncated ade6- $\Delta N / N$ allele at the endogenous locus. Arrows, B11 and B12, mark the location of primers. RT-PCR analysis performed on total RNA from wild-type, dcr1s, dcr1 1 rpb7-G150D double-mutant, and rpb7-G150D strains. Expression of the centromeric marker gene was undetectable in wild type, as compared with all three mutant strains where a distinct band was visible. Control reactions, without reverse transcriptase, were run to check for DNA contamination. (B$D$, left panels) ChIP analysis of cen1R:ura4 ${ }^{+}$marker gene at the centromeric $d g-d h$ repeat and the truncated ura4-DS/E allele at the endogenous locus. Competitive PCR was used in which one set of primers amplify two products: cen1R:ura4 $4^{+}$and ura4-DS/E. The relative fold enrichment was calculated by comparing the cen1R:ura $4^{+}$and ura4-DS/E ratio in DNA from the immunoprecipitated chromatin (IP) with input material (T). The ChIP method involves shearing of DNA that will cause shorter genes, such as ura4$D S / E$, to give rise to stronger signals. (Right panels) ChIP analysis of $d g-d h$ chromatin in wild type, $r p b 7-1$, and $s w i 6 \Delta$ at $25^{\circ} \mathrm{C}$. Duplex PCR was used to amplify two products: $d g$ and $f b p 1$. The relative fold enrichment was calculated by comparing the $d g$ and $f b p 1$ ratio in DNA from the immunoprecipitated chromatin (IP) with input material (T). (B) ChIP with $\mathrm{H} 3 \mathrm{~K} 9 \mathrm{me} 2$ antibodies at $25^{\circ} \mathrm{C}$ on wild type, $r p b 7-G 150 D$, and $c l r 4 \Delta$. (C) ChIP with Rad21-HA antibodies at $25^{\circ} \mathrm{C}$ on wild type, $r p b 7-G 150 D$, and swi6s. (D) ChIP with Swi6 antibodies at $25^{\circ} \mathrm{C}$ on wild type, rpb7-G150D, and swi6s. The numbers indicate the mean and standard deviations of three experiments. 
cen1R:ade6 ${ }^{+}$expression was undetectable in wild-type cells, but detectable in rpb7-G150D, dcr1s, and dcr1 $\operatorname{rpb} 7-G 150 D$ double-mutant cells. Dicer and RITS mutants show reduced dimethylation of histone $\mathrm{H} 3$ at Lys 9 (H3K9me2) and reduced binding of Swi6 and cohesin (Volpe et al. 2002, 2003; Verdel et al. 2004). We therefore tested if this was also defective in rpb7-G150D at the permissive temperature $\left(25^{\circ} \mathrm{C}\right)$. Chromatin immunoprecipitation (ChIP) analyses with rpb7-G150D strains showed strongly reduced levels of $\mathrm{H} 3 \mathrm{~K} 9 \mathrm{me} 2$, Swi6, and $\operatorname{Rad} 21$ cohesin associated with a ura4 marker gene inserted in the centromere repeats and at endogenous $d g-$ dh sequences (Fig. 2B-D; Supplementary Table S4). Loss of centromeric cohesin causes a typical lagging chromosome defect in anaphase cells (Pidoux et al. 2000; Bernard et al. 2001). Dicer and RITS mutant cells show this phenotype (Provost et al. 2002; Hall et al. 2003; Volpe et al. 2003). We found that $<0.1 \%$ of wild-type control and $16 \%$ of rpb7-G150D anaphase cells displayed lagging chromosomes at $25^{\circ} \mathrm{C}$. Thus, $r p b 7-G 150 D$ cells show defects in transcriptional silencing, heterochromatin assembly at centromeres, and chromosome segregation.

siRNAs homologous to $d g-d h$ repeats have been detected in wild-type cells (Reinhart and Bartel 2002) and transcripts from the reverse strand of $d g-d h$ are produced (Volpe et al. 2002). These transcripts are rapidly processed in wild-type cells and their levels are very low but they accumulate to high levels in $d c r 1 \Delta$ cells. To determine if the production of forward and reverse strand transcripts from the $d g-d h$ repeats is defective in $r p b 7$ G150D cells, a dcr1 $r p b 7-G 150 D$ double mutant was created, because such transcripts were expected to be undetectable in a Dicer context. The double mutant was similar to both $d c r 1 \Delta$ and $r p b 7-G 150 D$ regarding centromeric silencing defects (Fig. 2A). Accumulation of transcripts originating from centromeric repeats was assayed with strand specific RT-PCR, real-time PCR, and Northern analysis (Fig. 3B,C). Both reverse (real-time PCR; 276 times wild-type levels) and forward (596 times wild-type levels) $d g-d h$ transcripts were readily detectable in $d c r 1 \Delta$ cells (Fig. 3B,C). In rpb7-G150D cells, forward $d g-$ $d h$ transcripts were increased (real-time PCR; 16 times wild-type levels) and reverse transcripts were found by real-time PCR to be $25 \%$ reduced as compared with wild-type cells. It is known that forward strand $d g-d h$ transcripts are repressed by Swi6. Therefore, the increase of forward transcript levels in rpb7-G150D is likely to be a secondary effect, caused by the compromised heterochromatin, which allows more transcription. Importantly, transcript levels, particularly that of the reverse, remained low even in a dcr1 $\operatorname{rpb} 7-G 150 D$ double mutant at $25^{\circ} \mathrm{C}$, whereas both transcripts accumulated to high levels in dcr1s (Fig. 3B,C). The fact that reverse transcript levels remained low in the dcr1 $\operatorname{rpb} 7-G 150 D$ double mutant indicated that $\mathrm{Rpb} 7$ functions upstream of Dcrl in the RNAi pathway and may be required for the generation of centromeric pre-siRNAs. Recently, two other Pol II subunits, Rpb1 and Rpb2, were implicated in centromeric silencing (Kato et al. 2005; Schramke et al. 2005). Importantly $d c r 1 \Delta r p b 1-11$ and dcr1 1 rpb2-m203 mutants show no reduction of reverse $d g-d h$ transcripts as compared with $d c r 1 \Delta$ controls.

$3^{\prime}$-RACE mapping of centromeric $d g-d h$ transcripts was performed and the resulting sequences were aligned with genomic DNA sequences revealing that the reverse transcripts are polyadenylated (Fig. 3D) supporting the

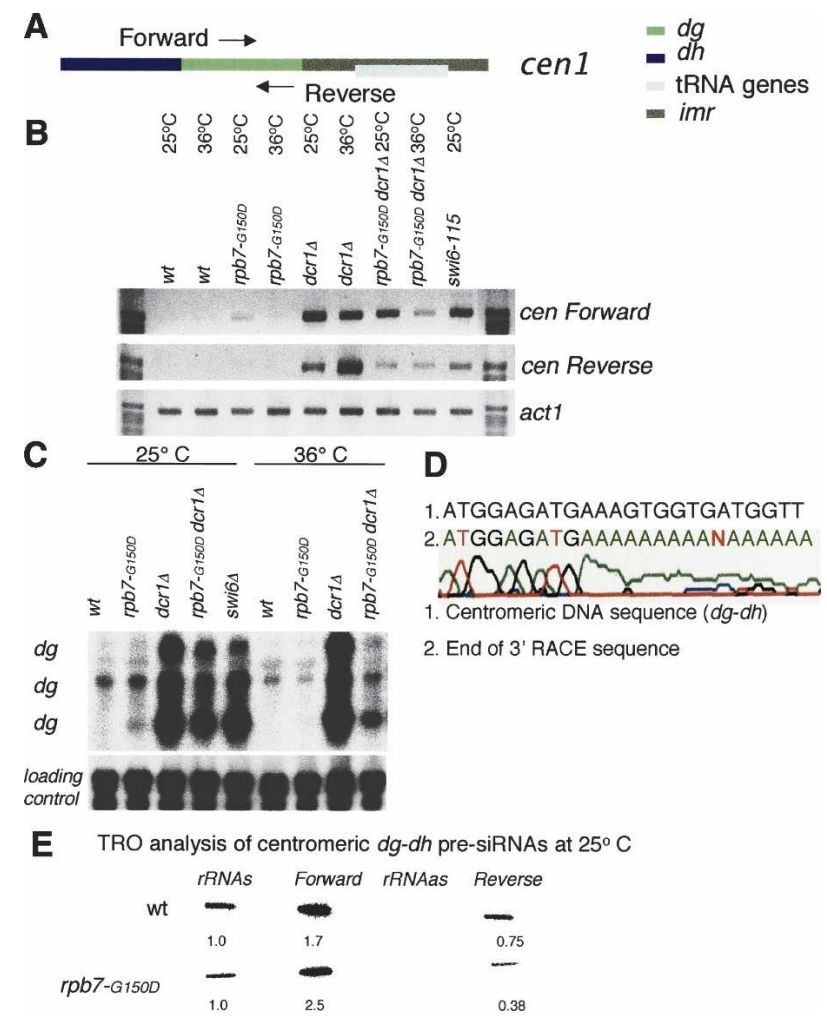

Figure 3. Pol II transcribes centromeric siRNA precursors. (A) Schematic representation of the centromeric otr1 repeat region of centromere 1. Arrows shows the primer locations. $(B)$ Strand-specific RT-PCR analysis of $d g-d h$ repeat transcripts. RNA was harvested from cells grown at $25^{\circ} \mathrm{C}$ and after a 1 -h shift to $36^{\circ} \mathrm{C}$. Forward and reverse $d g-d h$ transcripts were analysed, as indicated. Centromeric transcripts were not detected in wild-type cells. Actin serves as loading control. $(C)$ Northern analysis of noncoding centromeric $d g-d h$ transcripts. Centromeric transcripts were detected with a probe specific for the $d g-d h$ repeat. The loading control was actin/rDNA (nonspecific hybridization). (D) 3'-RACE mapping demonstrated that reverse $d g-d h$ transcripts were polyadenylated. DNA from $d g-d h$ repeat (1) aligned to $3^{\prime}$ end of $3^{\prime}$-RACE sequence. $(E)$ TRO analysis of $d g-d h$ transcripts at $25^{\circ} \mathrm{C}$. rRNA sense (s) and antisense (as) probes were used as controls. The numbers indicate the rRNA sense normalized $d g-d h$ RNA synthesis rate. Quantification is an average of two independent experiments.

idea that transcripts originating from centromeres indeed are transcribed by Pol II. We were also able to ChIP the $d g-d h$ region in wild-type and rpb7-G150D cells with antibody against Pol II (Supplementary Fig. S1). Thus, Pol II is associated with $d g-d h$ and Rpb7 is not required for Pol II recruitment to these centromere repeats.

To test if the altered $d g-d h$ transcript levels in $r p b 7$ G150D were due to changes in the rate of RNA synthesis, we carried out transcriptional run-on (TRO) analysis at $25^{\circ} \mathrm{C}$ of forward and reverse $d g-d h$ transcripts using Pol I transcribed rRNA probes as controls (Fig. 3E). These analyses show a reproducible twofold reduction of reverse synthesis and a 1.5-fold increase in forward synthesis in rpb7-G150D versus wild type. This finding is consistent with RT-PCR/Northern data (Fig. 3B,C) and indicates that initiation or elongation rates of reverse $d g-d h$ transcription are reduced in $r p b 7-G 150 D$ cells.

Previous studies have indicated a role for $\mathrm{Rpb} 7$ in ini- 
tiation of transcription. Together with Rpb4, Rpb7 forms a dissociable substructure of Pol II (Choder 2004) and it was found that Pol II lacking Rpb4/7 was inactive in promoter-directed initiation of transcription whereas addition of Rpb4/7 restored activity (Edwards et al. 1991). To test if Rpb4 has a role together with Rpb7 in RNAidirected centromeric functions, we expressed $r p b 4+$ with a high copy expression vector ( $p R E P 3 x-r p b 4+)$ and, interestingly, we were able to partially suppress both the microtubule-poison (TBZ) sensitivity and cen1R:ade6 silencing defects of rpb7-G150D by overexpression of Rpb4 (Supplementary Fig. S3). This suggested that Rpb4 and $\mathrm{Rpb} 7$ share a special role at fission yeast centromeres.

Rpb7 has been previously shown to affect transcriptional initiation of some genes in budding yeast (Choder 2004). Rpb7 interacts strongly in protein-DNA photocross-linking experiments with promoter DNA /Chen et al. 2004). Therefore to test if transcriptional initiation was defective in rpb7-G150D cells, we first mapped the $5^{\prime}$ end of the $d g-d h$ transcripts by $5^{\prime}$-RACE. The putative forward (For) and reverse (Rev) transcript promoters in the $d g-d h$ region were then cloned into a lacZ reporter plasmid (Forsburg 1993). Truncated versions of the Rev promoter were also constructed (Fig. 4A). The plasmids were introduced into wild-type, $r p b 7-G 150 D$, and $r p b 1$ 11 cells, and $\beta$-galactosidase assays were performed (Fig. 4B). Importantly, elongation, processing, and stability of the lacZ transcript were not affected since expression of $\beta$-galactosidase from the positive control nmt1-promoter-lacZ construct was not reduced in any of the mutants. It was clear from these data that the Rev promoter activity is strongly reduced at $25^{\circ} \mathrm{C}$ in $r p b 7-G 150 D$ but relatively unaffected in $r p b 1-11$ as compared with wild type. In expression profiling microarray analysis $r p b 1-11$ reduced transcription of 26 genes genome wide as compared with wild type (Schramke et al. 2005). Using the same microarray platform, normalizations, and cut-off value, we found that $r p b 7-G 150 D$ reduces expression of 51 genes as compared with wild type at $25^{\circ} \mathrm{C}$ (Supplementary Table S3). Therefore the two mutant Pol II enzymes are both only mildly compromised for transcription. Thus, the two mutant enzymes have a similar degree of genome-wide transcriptional defects, but only rpb7-G150D shows a defect in initiation of transcription from the Rev promoter.

As a consequence of reducing siRNA precursor synthesis, centromeric siRNA levels are expected to be reduced in the rpb7-G150D strain compared with wild type. In order to test this, centromeric siRNA levels were probed by Northern analysis (Fig. 4C) and, although readily detected in wild-type cells, they were undetectable in rpb7-G150D and dcr1s cells.

Taken together, the data presented represents the first direct evidence that pre-siRNA's are transcribed by Pol II. Pol II has previously been reported to transcribe microRNAs (Lee et al. 2004). However, microRNAs, which work in post-transcriptional gene silencing, are very different from centromeric pre-siRNAs, which are transcribed from heterochromatin and act in transcriptional gene silencing. Furthermore, our data suggest that a particular subunit of Pol II, Rpb7, is required for initiation of centromeric siRNA precursor transcription and that this reverse $d g-d h$ transcript is required to drive centromeric silencing. We speculate that the increased ssRNA-binding property of $r p b 7-G 150 D$ may inhibit initiation of
A

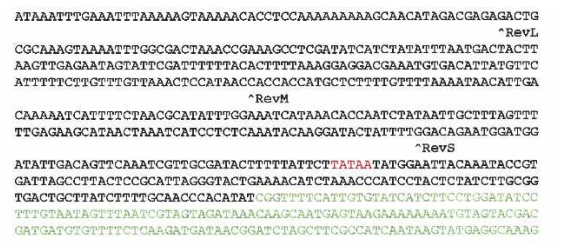

B
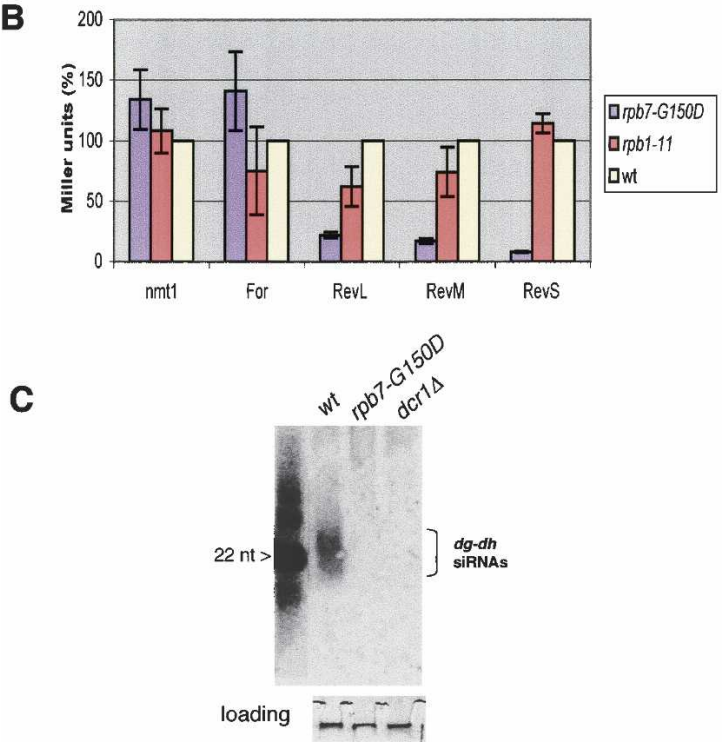

Figure 4. Rpb7 is specifically required to promote initiation of centromere repeat transcription and siRNA production at $25^{\circ} \mathrm{C}$. The transcription start site was revealed with $5^{\prime}$ RACE analysis of presiRNAs originating in the outer centromeric repeats of a $d c r 1 \Delta$ strain. $(A)$ Centromeric $d g-d h$ promoter fragments were cloned upstream of the lacZ reporter gene. RevL, RevM, and RevS are different truncated versions of the reverse (Rev) promoter starting at the carat $\uparrow$ and ending at the transcription start site (green). The position of the putative TATA box is indicated in red. $(B)$ Analysis of $d g-d h$ promoter gene expression using forward (For) and reverse (Rev) lacZ fusions in wild-type, $r p b 7-G 150 D$, and $r p b 1-11$ cells. $\beta$-Galactosidase activity (Miller Units) was assayed in cells grown at $25^{\circ} \mathrm{C}$. The $n m t 1$ promoter (pREP41X-lacZ) was used as a positive control. The mean activity of five independent transformed colonies is shown as a percentage of wild type. The error bars represent the standard deviation. $(C)$ Analysis of centromeric siRNA. (Top) Phosphorimages showing Northern blots of PEG precipitated small RNA extracted at $25^{\circ} \mathrm{C}$ from wild-type, $r p b 7-G 150 D$, and dcr1s cells. The Northern blots were probed with a centromeric $(d g-d h)$ probe. (Bottom) Gel image (loading) control representing the amount of PEG precipitated small RNA.

transcription by stalling the transition from Pol II initiation to elongation complex. The effect is specific to $r p b 7$ G150D, since two other fission yeast Pol II mutants do not have the same phenotype (Kato et al. 2005; Schramke et al. 2005). The CTD deleted mutant rpb1-11 has normal synthesis of pre-siRNAs, as well as siRNAs corresponding to centromeres (Schramke et al. 2005). A point mutation in the second largest Pol II subunit rpb2-m203 produces normal levels of pre-siRNAs but no centromeric siRNAs (Kato et al. 2005). Hence, both mutants are different than $r p b 7-G 150 D$, which has reduced levels of pre-siRNA and no centromeric siRNAs. Thus, remarkably, the three different subunits Rpb7, Rpb2, and Rpb1 affect distinct steps of the same pathway (presiRNA synthesis, generation of siRNA, and chromatin modifications). This may reflect an adaption of the RNAi 
machinery to the multisubunit structure of RNA pol II, to coordinate different mechanistic steps of the RNAidirected chromatin silencing pathway.

\section{Materials and methods}

Strains and media

Cells were grown in yeast extract supplemented with adenine (YES). Standard genetic techniques were used for crossing of strains. S. pombe strains used are listed in Supplementary Table S1.

\section{Expression profiling DNA microarrays}

Microarrays were purchased from Eurogentec and experiments were carried out as described (Xue et al. 2004). The microarray covers up to $99.5 \%$ of the annotated fission yeast genes. RNA was extracted from log phase cells using a standardized acid phenol method. cDNA was generated with a combination of $S$. pombe-specific primers and random hexamers and labeled with Сy3 and Cy5, respectively. Dye-swaps were done for all experiments. Hybridized slides were scanned using a Bio-Rad scanner and spots were quantified using ImageQuant version 4.2 (Imagene). The gene expression analysis was done with Genespring (Silicon Genetics). Normalization: To directly compare the rpb7-G150D $25^{\circ} \mathrm{C}$ and $36^{\circ} \mathrm{C}$ data sets, each gene's measured intensity was divided by the median of a list of positive control genes (luciferase spiking controls). To compare rpb7G150D $25^{\circ} \mathrm{C}$ with $r p b 1-11$ expresion profiles (Schramke et al. 2005) the Lowess normalization was used (Xue et al. 2004).

$R T-P C R$

Log phase cells were subjected to RNA extraction by standard acid phenol extraction or with RNeasy Mini kit for Preparation (QIAGEN). Before RT-PCR, all RNA samples were DNase treated (DNaseI, Invitrogen). Superscript first-strand synthesis system (Invitrogen) or OneStep RTPCR Kit (QIAGEN) was used for RT-PCR. In strand-specific RT-PCR reactions only one primer, forward or reverse, was added to the RT reaction. Control reactions lacking RT were run for all RNA samples. Real-time PCR for cen forward, reverse and actin controls was carried out using a MyIQ (Bio-Rad) single-color apparatus.

ChIP

ChIP was performed as previously described except for the following modification: Cells were spheroplasted at 108 cells/mL in PEMS (100 $\mathrm{mM}$ Pipes at $\mathrm{pH} 7,1 \mathrm{mM}$ EDTA, $1 \mathrm{mM} \mathrm{MgCl} 2,1.2 \mathrm{M}$ sorbitol) with 0.4 $\mathrm{mg} / \mathrm{mL}$ Zymolyase-100T for $25 \mathrm{~min}$ at $36^{\circ} \mathrm{C}$. Cells were washed twice in PEMS, and cell pellets were frozen at $-20^{\circ} \mathrm{C}$. Thereafter the standard ChIP procedure was followed. Quantitation of bands was performed using the Eastman Kodak Co. EDAS 290 system and 1D Image Analysis software.

Immunofluorescence microscopy

Cell growth, fixation in $3.8 \%$ paraformaldehyde, staining, detection of $\alpha$-tubulin, collection of images, and spindle length measurements have been described (Mitsuzawa et al. 2003).

\section{Northern blots}

Ten micrograms of total RNA, prepared as described above, was resolved on $6.3 \%$ formaldehyde gels containing $1 \%$ agarose and blotted overnight to a Hybond-XL membrane (Amersham Biosciences). DNA probes, complementary to centromeric $d g-d h$ repeats and actin, were generated with Random Primed DNA Labeling Kit (Roche). The probes were hybridized to the membranes overnight at $65^{\circ} \mathrm{C}$ in a rotating oven and washed according to the protocol provided by the manufacturer of the membrane.

$3^{\prime}-$ and $5^{\prime}-R A C E$

$3^{\prime}$ - and 5'-RACE mapping of RNA transcripts from strain 978 was done according to protocol from the manufacturer, RACE System for Rapid Amplification of cDNA Ends version 2.0 (Invitrogen). Sequencing was done with ABI Prism BigDye Terminator Cycle Sequencing Ready Reactions Kits, Original and version 2.0 (AB Applied Biosystems).

\section{TRO assay}

TRO assays were carried out as described (Alen et al. 2002). Seven-hundred-nucleotide single-stranded MAXIscript probes for rRNA and $d g-d h$ region were used.
Small RNA preparations and detection

Log phase cells were subjected to RNA extraction by standard acid phenol extraction followed by PEG precipitation. Samples were resuspended in $50 \%$ formamide and separated on a $17.5 \%$ Urea-denaturating polyacrylamide gel. A ${ }^{32} \mathrm{P}$-DNA probe, complementary to centromeric $d g-d h$ repeats, was generated with Random Primed DNA Labeling Kit (Roche). The probe was hybridized to the membranes overnight at $42^{\circ} \mathrm{C}$ in a rotating oven and washed twice with $2 \times$ SSC $2 \%$ SDS at $50^{\circ} \mathrm{C}$. Phosphorscreen or films were exposed for a minimum of $3 \mathrm{~h}$ up to $3 \mathrm{~d}$. DNA Oligonucleotides 22 nucleotides (nt) in length were used as a marker.

\section{RNA filter assay}

Centromeric $d g-d h$ repeats PCR-fragments were generated with T7 promoters at both ends. Radioactively labeled RNA was produced from these templates with the MAXIscript in vitro transcription Kit from Ambion. Pol II was purified from strains 303 and 801 and subjected to transcription assays as described previously (Spahr et al. 2003). Pol II binding to RNA was assayed by nitrocellulose filter binding in a $25 \mu \mathrm{L}$ reaction volume. Proteins were incubated with in vitro transcribed RNA $(40,000$ counts per minute) in RNA-binding buffer ( $5 \mathrm{mM}$ magnesium acetate, 2.5 mM magnesium sulfate, $3.7 \mathrm{mM}$ EDTA, $37 \mathrm{mM}$ Hepes-KOH at $\mathrm{pH} 7.6$, $100 \mathrm{mM}$ potassium acetate, $1.25 \mathrm{mM}$ dithiothreitol, and RNase inhibitors) for $30 \mathrm{~min}$ at $36^{\circ} \mathrm{C}$. The mix was transferred to a nitrocellulose membrane (Schleicher and Schuell, Protran $0.45 \mu \mathrm{M}$ ), washed twice with 1 mL RNA-binding buffer without RNase inhibitor, and measured in a liquid scintillation counter (Wallac 1410).

Purification of RNA Pol II

Purification of RNA Pol II was carried out according to Spahr et al. (2003). Western blotting with Rpb7-specific (Santa Cruz) and Rpbl-specific (Neoclone) antibodies was performed according to the manufacturers instructions.

$\beta$-Galactosidase activity assay

Cells containing the pREP-lacZ constructs (Fig. 4B) were grown in PMG medium lacking leucine and thiamine to mid-logarithmic phase at $25^{\circ} \mathrm{C}$. Units were defined as equal to $\left(1000 \times \mathrm{OD}_{414}\right) \times\left(\mathrm{min} \times \mathrm{mL} \times \mathrm{OD}_{595}\right)^{-1}$. The $n m t 1$ promoter (pREP41X-lacZ) was used as a positive control (Forsburg 1993).

\section{Acknowledgments}

We thank Thomas Jenuwein for contributing with $\alpha-\mathrm{H} 3 \mathrm{~K} 9 \mathrm{Me} 2$ and Susan Forsburg for providing plasmids. K.E. is a Royal Swedish Academy of Sciences Research Fellow supported by a grant from the Knut and Alice Wallenberg Foundation. K.E is funded by Cancerfonden 4284-B02-04XBB and VR-M 31X-12562, VR-NT 621-2002-4311 grants. C.M.G. is funded by grants from Swedish Cancer Society and the Swedish Foundation for Strategic Research. R.C.A. is a Wellcome Trust Principal Research Fellow (065061), and M.P. is funded by a Wellcome Trust Prize Studentship (067844). R.C.A and K.E. are members of the EC FP6 Network "The Epigenome" LSHG-CT-2004-503433.

\section{References}

Alen, C., Kent, N.A., Jones, H.S., O'Sullivan, J., Aranda, A., and Proudfoot, N.J. 2002. A role for chromatin remodeling in transcriptional termination by RNA polymerase II. Mol. Cell 10: 1441-1452.

Allshire, R.C., Nimmo, E.R., Ekwall, K., Javerzat, J.P., and Cranston, G. 1995. Mutations derepressing silent centromeric domains in fission yeast disrupt chromosome segregation. Genes \& Dev. 9: 218-233.

Bernard, P., Maure, J.F., Partridge, J.F., Genier, S., Javerzat, J.P., and Allshire, R.C. 2001. Requirement of heterochromatin for cohesion at centromeres. Science 294: 2539-2542.

Bernstein, E., Caudy, A.A., Hammond, S.M., and Hannon, G.J. 2001. Role for a bidentate ribonuclease in the initiation step of RNA interference. Nature 409: 363-366.

Chen, B.S., Mandal, S.S., and Hampsey, M. 2004. High-resolution protein-DNA contacts for the yeast RNA polymerase II general transcription machinery. Biochemistry 43: 12741-12749.

Choder, M. 2004. Rpb4 and Rpb7: Subunits of RNA polymerase II and beyond. Trends Biochem. Sci. 29: 674-681.

Cleveland, D.W., Mao, Y., and Sullivan, K.F. 2003. Centromeres and 
Djupedal et al.

kinetochores: From epigenetics to mitotic checkpoint signaling. Cell 112: 407-421.

Edwards, A.M., Kane, C.M., Young, R.A., and Kornberg, R.D. 1991. Two dissociable subunits of yeast RNA polymerase II stimulate the initiation of transcription at a promoter in vitro. J. Biol. Chem. 266: 71-75.

Ekwall, K., Cranston, G., and Allshire, R.C. 1999. Fission yeast mutants that alleviate transcriptional silencing in centromeric flanking repeats and disrupt chromosome segregation. Genetics 153: 1153-1169.

Fire, A., Xu, S., Montgomery, M.K., Kostas, S.A., Driver, S.E., and Mello, C.C. 1998. Potent and specific genetic interference by doublestranded RNA in Caenorhabditis elegans. Nature 391: 806-811.

Forsburg, S.L. 1993. Comparison of Schizosaccharomyces pombe expression systems. Nucleic Acids Res. 21: 2955-2956.

Fukagawa, T., Nogami, M., Yoshikawa, M., Ikeno, M., Okazaki, T., Takami, Y., Nakayama, T., and Oshimura, M. 2004. Dicer is essential for formation of the heterochromatin structure in vertebrate cells. Nat. Cell Biol. 6: 784-791.

Hall, I.M., Noma, K., and Grewal, S.I. 2003. RNA interference machinery regulates chromosome dynamics during mitosis and meiosis in fission yeast. Proc. Natl. Acad. Sci. 100: 193-198.

Herr, A.J., Jensen, M.B., Dalmay, T., and Baulcombe, D.C. 2005. RNA polymerase IV directs silencing of endogenous DNA. Science 308: $118-120$.

Kanellopoulou, C., Muljo, S.A., Kung, A.L., Ganesan, S., Drapkin, R., Jenuwein, T., Livingston, D.M., and Rajewsky, K. 2005. Dicer-deficient mouse embryonic stem cells are defective in differentiation and centromeric silencing. Genes \& Dev. 19: 489-501.

Kato, H., Goto, D., Martienssen, R., Urano, T., Furukawa, K., and Murakami, Y. 2005. RNA polymerase II is required for RNAi-dependent heterochromatin assembly. Science 309: 467-469.

Lee, Y., Kim, M., Han, J., Yeom, K.H., Lee, S., Baek, S.H., and Kim, V.N. 2004. MicroRNA genes are transcribed by RNA polymerase II. EMBO I. 23: 4051-4060

Mitsuzawa, H., Kanda, E., and Ishihama, A. 2003. Rpb7 subunit of RNA polymerase II interacts with an RNA-binding protein involved in processing of transcripts. Nucleic Acids Res. 31: 4696-4701.

Mochizuki, K., Fine, N.A., Fujisawa, T., and Gorovsky, M.A. 2002. Analysis of a piwi-related gene implicates small RNAs in genome rearrangement in tetrahymena. Cell 110: 689-699.

Onodera, Y., Haag, J.R., Ream, T., Nunes, P.C., Pontes, O., and Pikaard, C.S. 2005. Plant nuclear RNA polymerase IV mediates siRNA and DNA methylation-dependent heterochromatin formation. Cell 120: 613-622.

Pal-Bhadra, M., Bhadra, U., and Birchler, J.A. 2002. RNAi related mechanisms affect both transcriptional and posttranscriptional transgene silencing in Drosophila. Mol. Cell 9: 315-327.

Pidoux, A.L., Uzawa, S., Perry, P.E., Cande, W.Z., and Allshire, R.C. 2000. Live analysis of lagging chromosomes during anaphase and their effect on spindle elongation rate in fission yeast. J. Cell Sci. 113 Pt 23: 4177-4191.

Provost, P., Silverstein, R.A., Dishart, D., Walfridsson, J., Djupedal, I., Kniola, B., Wright, A., Samuelsson, B., Radmark, O., and Ekwall, K. 2002. Dicer is required for chromosome segregation and gene silencing in fission yeast cells. Proc. Natl. Acad. Sci. 99: 16648-16653.

Reinhart, B.J. and Bartel, D.P. 2002. Small RNAs correspond to centromere heterochromatic repeats. Science 297: 1831.

Sakurai, H. and Ishihama, A. 1997. Gene organization and protein sequence of the small subunits of Schizosaccharomyces pombe RNA polymerase II. Gene 196: 165-174.

Schramke, V., Sheedy, D., Denli, A., Bonilla, C., Ekwall, K., Hannon, G., and Allshire, R. 2005. RNAi-mediated chromatin modification is coupled to RNA pol II transcription. Nature 435: 1275-1279.

Spahr, H., Khorosjutina, O., Baraznenok, V., Linder, T., Samuelsen, C.O., Hermand, D., Makela, T.P., Holmberg, S., and Gustafsson, C.M. 2003. Mediator influences Schizosaccharomyces pombe RNA polymerase II-dependent transcription in vitro. J. Biol. Chem. 278: 5130151306.

Todone, F., Brick, P., Werner, F., Weinzierl, R.O., and Onesti, S. 2001. Structure of an archaeal homolog of the eukaryotic RNA polymerase II RPB4/RPB7 complex. Mol. Cell 8: 1137-1143.

Verdel, A., Jia, S., Gerber, S., Sugiyama, T., Gygi, S., Grewal, S.I., and Moazed, D. 2004. RNAi-mediated targeting of heterochromatin by the RITS complex. Science 303: 672-676.

Volpe, T.A., Kidner, C., Hall, I.M., Teng, G., Grewal, S.I., and Martienssen, R.A. 2002. Regulation of heterochromatic silencing and histone H3 lysine-9 methylation by RNAi. Science 297: 1833-1837.

Volpe, T., Schramke, V., Hamilton, G.L., White, S.A., Teng, G., Martienssen, R.A., and Allshire, R.C. 2003. RNA interference is required for normal centromere function in fission yeast. Chromosome Res. 11: $137-146$

Xue, Y., Haas, S.A., Brino, L., Gusnanto, A., Reimers, M., Talibi, D. Vingron, M., Ekwall, K., and Wright, A.P. 2004. A DNA microarray for fission yeast: Minimal changes in global gene expression after temperature shift. Yeast 21: 25-39.

Zamore, P.D., Tuschl, T., Sharp, P.A., and Bartel, D.P. 2000. RNAi: Double-stranded RNA directs the ATP-dependent cleavage of mRNA at 21 to 23 nucleotide intervals. Cell 101: 25-33.

Zilberman, D., Cao, X., and Jacobsen, S.E. 2003. ARGONAUTE4 control of locus-specific siRNA accumulation and DNA and histone methylation. Science 299: 716-719. 


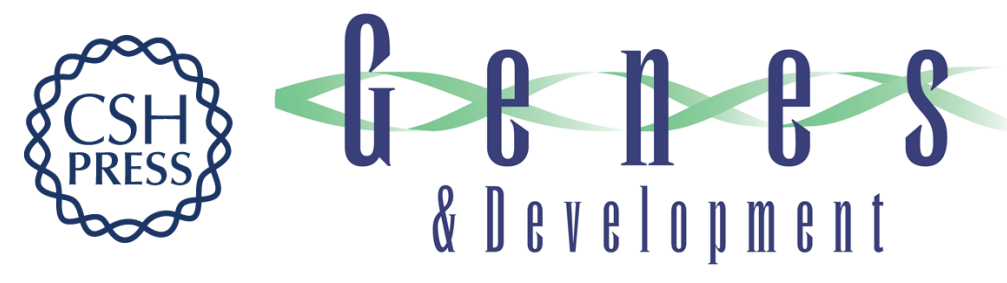

\section{RNA Pol II subunit Rpb7 promotes centromeric transcription and RNAi-directed chromatin silencing}

Ingela Djupedal, Manuela Portoso, Henrik Spåhr, et al.

Genes Dev. 2005, 19:

Access the most recent version at doi:10.1101/gad.344205

Supplemental
Material http://genesdev.cshlp.org/content/suppl/2005/10/03/19.19.2301.DC1

References This article cites 34 articles, 16 of which can be accessed free at:

http://genesdev.cshlp.org/content/19/19/2301.full.html\#ref-list-1

License

Email Alerting

Receive free email alerts when new articles cite this article - sign up in the box at the top

Service

right corner of the article or click here.

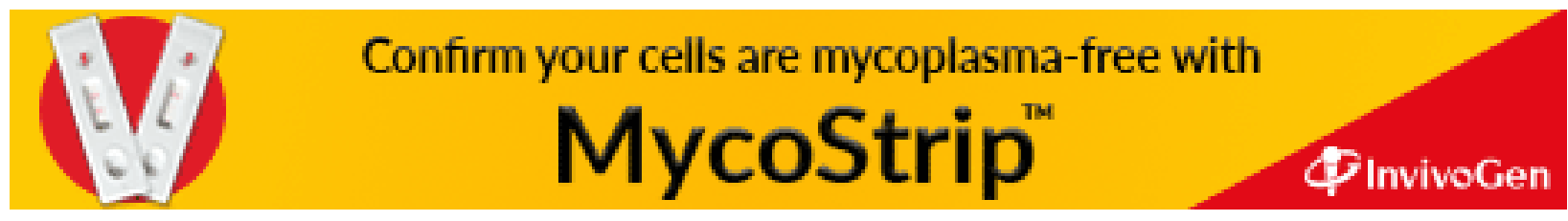

